\title{
Polymerization-Induced Self-Assembly based on ATRP in Supercritical Carbon Dioxide
}

\author{
Abdullah Alzahrani, ${ }^{1}$ Dewen Zhou, ${ }^{2}$ Rhiannon P. Kuchel, ${ }^{3}$ Per B. Zetterlund, ${ }^{*}, 2$ \\ and Fawaz Aldabbagh ${ }^{*}, 1,4$ \\ ${ }^{1}$ School of Chemistry, National University of Ireland Galway, University Road, Galway, H91 TK33, \\ Ireland \\ ${ }^{2}$ Centre for Advanced Macromolecular Design (CAMD), School of Chemical Engineering, The \\ University of New South Wales, Sydney, NSW 2052, Australia \\ ${ }^{3}$ Mark Wainwright Analytical Centre, University of New South Wales, Sydney, NSW 2052, Australia. \\ ${ }^{4}$ Department of Pharmacy, School of Life Sciences, Pharmacy \& Chemistry, Kingston University, \\ Penrhyn Road, Kingston upon Thames, KT1 2EE, UK
}

\begin{abstract}
Polymerization-induced self-assembly (PISA) based on atom transfer radical polymerization (ATRP) has been performed in supercritical carbon dioxide $\left(\mathrm{scCO}_{2}\right)$ using a bromo-terminated poly(dimethylsiloxane) (PDMS-Br) species as macroinitiator (solvophilic first block) and poly(benzyl methacrylate) as the solvophobic second block. The polymerizations proceeded to high conversion with good control/livingness. Transmission electron microscopy revealed the formation of the first higher order morphologies in $\mathrm{scCO}_{2}$, namely worms and likely vesicles. Interestingly, highly regular microphase separated multilayered morphology was also observed, which are not observed with PISA carried out in conventional solvents. Overall, the morphologies formed cannot be rationalized based on simple considerations of the relative block lengths and packing parameters, as is typically the case in dispersion PISA in common solvents such as water and water/alcohol. Seemingly, the unique properties of $\mathrm{scCO}_{2}$ lead to different polymer domains.
\end{abstract}


Over the past decade there has been intense interest in the preparation of non-spherical polymer particles using polymerization-induced self-assembly (PISA). ${ }^{1-28}$ PISA is typically implemented as a reversible deactivation radical polymerization (RDRP) in the form of a dispersion polymerization. Most commonly reversible addition-fragmentation chain transfer (RAFT) polymerization is used to extend a solvophilic macroRAFT agent (also acting as steric stabilizer) with a dissolved monomer, which forms the solvophobic polymer core. ${ }^{1-2,8-10,13-16 \text {, }}$ 18-20, 22, 24, 27-28 PISA can also be implemented as an emulsion polymerization if the monomer is insoluble in the continuous phase. ${ }^{7,23}$ Other RDRP processes have been exploited in connection with PISA, such as atom transfer radical polymerization (ATRP), ${ }^{3-4,21}$ nitroxide-mediated radical polymerization (NMP), ${ }^{5,23}$ organotellurium-mediated living radical polymerization (TERP), ${ }^{7}$ and $\mathrm{Cu}(0)$-mediated radical polymerization, ${ }^{12}$ as well as recently non-living radical polymerization in the form of addition-fragmentation chain transfer (AFCT) polymerization. ${ }^{25-}$ ${ }^{26}$ PISA has been carried out in non-polar solvents, ${ }^{1-2,8,10,14-17,20}$ as well as in more conventional polar media. For instance, higher order non-spherical morphologies, including thermallysensitive worm-phases, were obtained using RAFT dispersion polymerizations in long chain alkanes via chain extensions of fatty acid-chain containing RAFT agents with benzyl methacrylate (BzMA). ${ }^{8,10,20}$ RAFT dispersion PISA has also been carried out in ionic liquid, a recyclable green solvent, giving nanoaggregates of multiple morphologies. ${ }^{11}$

Supercritical carbon dioxide $\left(\mathrm{scCO}_{2}\right)$ is a well-known benign effective replacement for environmentally damaging volatile organic compounds (VOCs). ${ }^{29-30} \mathrm{CO}_{2}$ is cheap and nonflammable with its utility making positive use of a green-house gas. $\mathrm{ScCO}_{2}$ holds considerable merit as a medium for heterogeneous RDRP, in particular precipitation and dispersion polymerizations, ${ }^{31}$ given that most vinyl monomers are soluble in $\mathrm{scCO}_{2}$, but the resultant polymer becomes insoluble at a critical degree of polymerization $\left(J_{\text {crit }}\right){ }^{32}$ Additional advantages of radical polymerization in $\mathrm{scCO}_{2}$ include the easy adjustment of polymer solubility by altering of pressure and monomer loading, and at high conversions venting of the $\mathrm{CO}_{2}$ leaves a dry polymer powder, which circumvents the requirement for VOC. There are a plethora of reports on dispersion RDRP in $\mathrm{scCO}_{2}$, which are based on two approaches: $(i)$ the use of a separate $\mathrm{scCO}_{2}$-soluble steric stabilizer, ${ }^{33-37}$ and (ii) the use of a $\mathrm{scCO}_{2}$-soluble first block that is subsequently chain extended via RDRP in an approach that is analogous to PISA in conventional media. ${ }^{38-47}$ Amphorous fluoropolymers and polysiloxanes are polymers with appreciable solubility in $\mathrm{scCO}_{2}$, and are usually used as macroinitiators for dispersion polymerizations in $\mathrm{scCO}_{2}$. In 1999, Matyjaszewski and DeSimone carried out the first dispersion RDRP in $\mathrm{scCO}_{2}$ by extending bromine-terminated poly(1,1-dihydroperfluorooctyl 
methacrylate-Br) with methyl methacrylate (MMA) and 2-(dimethylamino)ethyl methacrylate using ATRP. ${ }^{38}$ Okubo and co-workers conducted dispersion ATRP of MMA in $\mathrm{ScCO}_{2}$ using bromo-terminated poly(dimethylsiloxane, PDMS-Br), and referred to the $\mathrm{scCO}_{2}$-soluble block as inistab (initiator + stabilizer). ${ }^{39}$ The inistab-concept was consequently used in $\mathrm{scCO}_{2}$ for NMP and iodine transfer dispersion polymerizations using PDMS and fluorinated polymeric alkoxyamines, which were extended with styrene $(\mathrm{St})$ and MMA. ${ }^{40-43}$ Howdle and co-workers reported RAFT dispersion polymerizations of MMA and $N$-vinyl pyrrolidine by chain extending fluorinated polymer, PDMS, and polyvinylalkylates. ${ }^{45-47}$ However, in all reported dispersion $\mathrm{RDRP}$ in $\mathrm{scCO}_{2}$, block copolymer self-assembly has been limited to spherical morphologies.

In the present work, we report the synthesis of a range of higher order morphologies, including worms and vesicles, via PISA in $\mathrm{scCO}_{2}$ implemented with ATRP. There are to date to the best of our knowledge no reports on the dispersion polymerization of $\mathrm{BzMA}$ in $\mathrm{scCO}_{2}$, despite its frequent use for PISA in conventional media. ${ }^{8,10,17,20-21,25}$ Chain extensions with BzMA lead to a relatively low glass transition temperature $\left(T_{\mathrm{g}}\right)$ in the resultant polymer compared with e.g. St and MMA. The lower $T_{\mathrm{g}}$ is associated with increased chain mobility in the core facilitating morphology transition from spheres to worm-like and vesicular morphologies. Herein, PISA is conducted as dispersion ATRP of BzMA in $\mathrm{scCO}_{2}$ using a $\mathrm{scCO}_{2}$ soluble inistab species (PDMS-Br) to generate block copolymer particles of various morphologies, including particles with microphase separated multilayered morphology, in onestep at monomer loadings as high as $65 \mathrm{v} / \mathrm{v}(\%)$. The procedure circumvents the requirement for an aqueous phase or VOCs and conveniently yields polymer particles as a dry powder on venting of $\mathrm{CO}_{2}$ after polymerization. 
Table 1. Summary of molecular weight and conversion data of the specific samples subjected to TEM analysis (dispersion ATRP of BzMA at $80^{\circ} \mathrm{C}$ and $30 \mathrm{MPa}$ ).

\begin{tabular}{|c|c|c|c|c|c|c|c|}
\hline \multicolumn{2}{|c|}{$\begin{array}{r}\operatorname{Run}^{a}[\mathrm{BzMA}] / \\
{[\mathrm{PDMS}-\mathrm{Br}]}\end{array}$} & $\begin{array}{c}\text { BzMA } \\
\text { loading } \\
\text { v/v( } \%)\end{array}$ & Polymer $^{b}$ & $M_{\mathrm{n}, \mathrm{th}}{ }^{c}$ & $\begin{array}{l}\text { Conv. }^{d} \\
(\%)^{d}\end{array}$ & $M_{\mathrm{n}}^{e}$ & $\overline{D^{e}}$ \\
\hline 1 & 400 & 35 & PDMS- $b$-PBzMA 266 & 52550 & 67 & 52200 & 1.33 \\
\hline 2 & 400 & 35 & PDMS- $b$-PBzMA 359 & 70900 & 93 & 68450 & 1.34 \\
\hline 3 & 168 & 35 & PDMS- $b$-PBzMA 138 & 31400 & 88 & 29650 & 1.25 \\
\hline 4 & 280 & 35 & PDMS- $b$-PBzMA ${ }_{212}$ & 45900 & 83 & 42650 & 1.25 \\
\hline 5 & 168 & 50 & PDMS- $b-$ PBzMA $_{167}$ & 33200 & 94 & 34800 & 1.33 \\
\hline 6 & 168 & 65 & 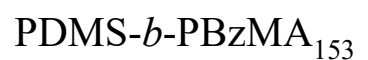 & 31700 & 89 & 32300 & 1.30 \\
\hline
\end{tabular}

${ }^{a}$ All polymerization contained [PDMS-Br]/[CuBr]/[HMTETA] $=1: 1.5: 1.5$ and were for $24 \mathrm{~h}$, except Run 2 was 36 h. ${ }^{b}$ The degree of polymerization of the BzMA block was obtained by deducting the $M_{\mathrm{n}}(\mathrm{GPC})$ of PDMS-Br $(5350 \mathrm{~g} / \mathrm{mol})$. The Br-end group is not represented. ${ }^{c}$ Calculated according to equation 1 (see SI). ${ }^{d}$ Conversion determined by gravimetry. ${ }^{e}$ From GPC analysis using linear polystyrene standards.

The appreciable solubility of the monomer $\mathrm{BzMA}$ in $\mathrm{scCO}_{2}$ (a requirement for a dispersion polymerization) was visually confirmed using a $100 \mathrm{~mL}$ stainless steel reactor with $180^{\circ}$ inline sapphire windows, where at $80^{\circ} \mathrm{C}$ and $30 \mathrm{MPa}$ a transparent solution was observed using 35$65 \mathrm{v} / \mathrm{v}(\%)$ BzMA loadings. ATRP dispersion polymerizations were subsequently carried out under these conditions in a window-less $25 \mathrm{~mL}$ stainless steel reactor at $35 \mathrm{v} / \mathrm{v}(\%)$ of monomer, initially using [BzMA]:[PDMS-Br]:[CuBr]:[1,1,4,7,10,10-hexmethyltriethylenetetramine; HMTETA $]=400: 1: 1.5: 1.5$ (Table 1; Runs 1 and 2; same polymerization receipe taken to different conversions). The inistab species PDMS-Br $\left(M_{\mathrm{n}}=5350 \mathrm{~g} / \mathrm{mol} ; \varnothing=1.12\right)$ was obtained by condensing commercial PDMS-OH with 2-bromoisobutyryl bromide. ${ }^{39,} 48$ The polymerizations proceeded to near complete conversion (93\%) in $36 \mathrm{~h}$ with excellent controlled/living character as indicated by narrow molecular weight distributions (MWDs) with $Ð<1.35$ and $M_{\mathrm{n}}$ in close agreement with theoretical $\left(M_{\mathrm{n}, \mathrm{th}}\right)$ values (Figure 1; note however the GPC data are subject to calibration error using linear polystyrene standards). At the end of the polymerizations, ${ }^{1} \mathrm{H}$ NMR analysis confirmed the complete removal of unreacted monomer by washing the polymer with $\mathrm{scCO}_{2}$ and venting of the $\mathrm{CO}_{2}$ (containing unreacted monomer). The dry polymer powders (Fig. S1) obtained at the highest conversions (67\% after $24 \mathrm{~h}$ (Run 
1) and 93\% after $36 \mathrm{~h}$ (Run 2)) were redispersed in pentane, and the particles were subsequently observed by TEM (Fig. 2).

(i)



(ii)

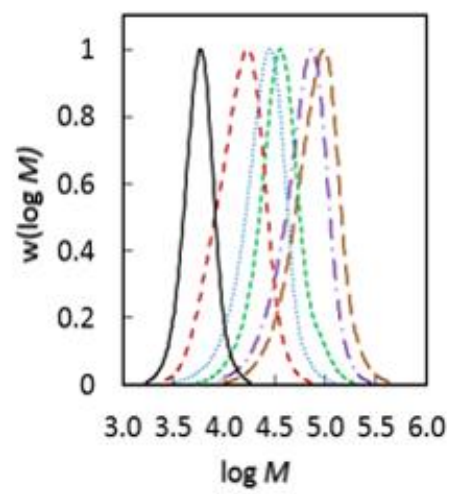

(iii)

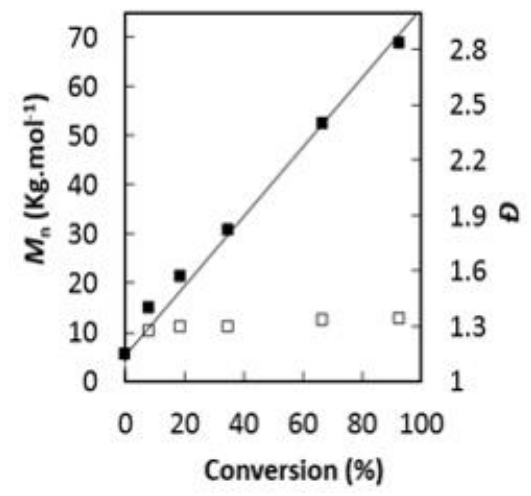

Fig. 1. ATRP dispersion of $35 \mathrm{v} / \mathrm{v}(\%)$ BzMA in $\mathrm{scCO}_{2}$ at $80{ }^{\circ} \mathrm{C}$ and $30 \mathrm{MPa}$ using [BzMA]:[PDMS-Br]:[CuBr]:[HMTETA] = 400:1:1.5:1.5. (i) Conversion vs. time data; (ii) MWDs corresponding to PDMS-Br (black solid line) and polymerizations at conversions of 11 (6 h), 25 (12 h), 40 (16 h), 67 (24 h) and 93\% (36 h) (the latter two corresponding to Run 1 and Run 2); (iii) $M_{\mathrm{n}}(\square)$ and $Ð(\square)$ vs. conversion. $M_{\mathrm{n}, \mathrm{th}}$ is the continuous line calculated according to equation 1 (see SI).

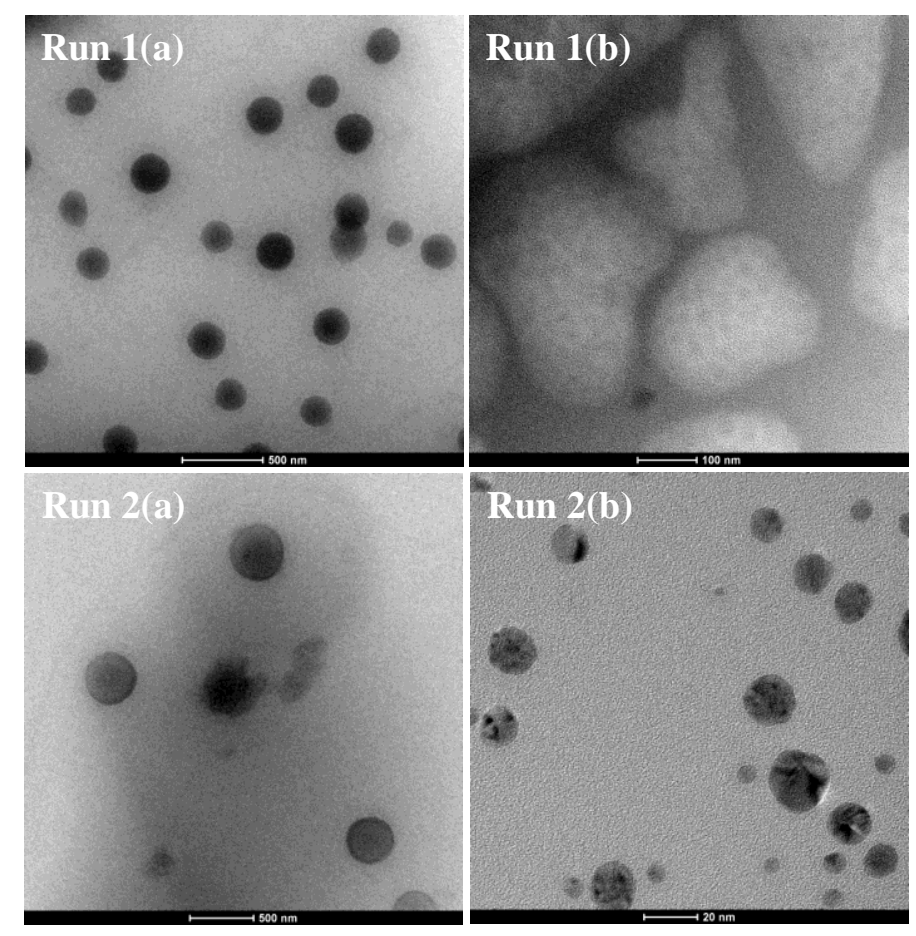

Fig. 2. TEM images of PDMS- $b$-PBzMA particles from Run 1 and Run 2 (Table 1) corresponding to dispersion ATRP at $35 \mathrm{v} / \mathrm{v}(\%) \mathrm{BzMA}$ in $\mathrm{scCO}_{2}$ at $80{ }^{\circ} \mathrm{C}$ and $30 \mathrm{MPa}$. Scale bars are $500 \mathrm{~nm}$ (Run 1(a)), $100 \mathrm{~nm}$ (Run 1(b)), $500 \mathrm{~nm}$ (Run 2(a)) and $20 \mathrm{~nm}$ (Run 2(b)). 
At $67 \%$ conversion (Run 1; DP PBzMA block $=266$ ), the main population comprises near spherical particles with approximate size of $200 \mathrm{~nm}$ (Run 1(a)), although non-spherical particles with distinct internal morphology (phase separation) can also be observed (Run 1(b)). At near full conversion of 93\%, the phase separation appears more pronounced (Run 2; DP PBzMA block = 359; Fig. 2; Run 2(b)). At this conversion, two distinct solid particle populations were observed of approximate size $300 \mathrm{~nm}$ (Fig. 2; Run 2(a)) and 5-30 nm (Fig. 2; Run 2(b)). It seems the particles observed at $67 \%$ conversion have increased in size at $93 \%$ conversion, and phase separated regions have become smaller spherical particles at higher DP. The effect of the length of the core-forming $\mathrm{CO}_{2}$-phobic block on the morphology was investigated by reducing the monomer to macroinitiator ratio [BzMA]/[PDMS-Br] while keeping all other parameters constant (Run 3 and Run 4). Narrow MWDs with lower DP values of 138 (Run 3) and 212 (Run 4) for the PBzMA block were obtained after $24 \mathrm{~h}$ (Fig. S2). TEM imaging of Run 3 reveals the presence of a population of very small particles $(<10 \mathrm{~nm})$ as well as larger near spherical particles of diameters in the range of $100-500 \mathrm{~nm}$ that are most likely vesicles, but also wormlike particles. The relatively low $T_{\mathrm{g}}$ of the PBzMA block as well as unreacted BzMA monomer facilitate transition to higher order morphologies. Run 4 resulted in larger irregularly shaped particles of micron-scale dimensions. Interestingly, well-ordered multilayered lamellar phase separated domains on the nanoscale were clearly observable. 


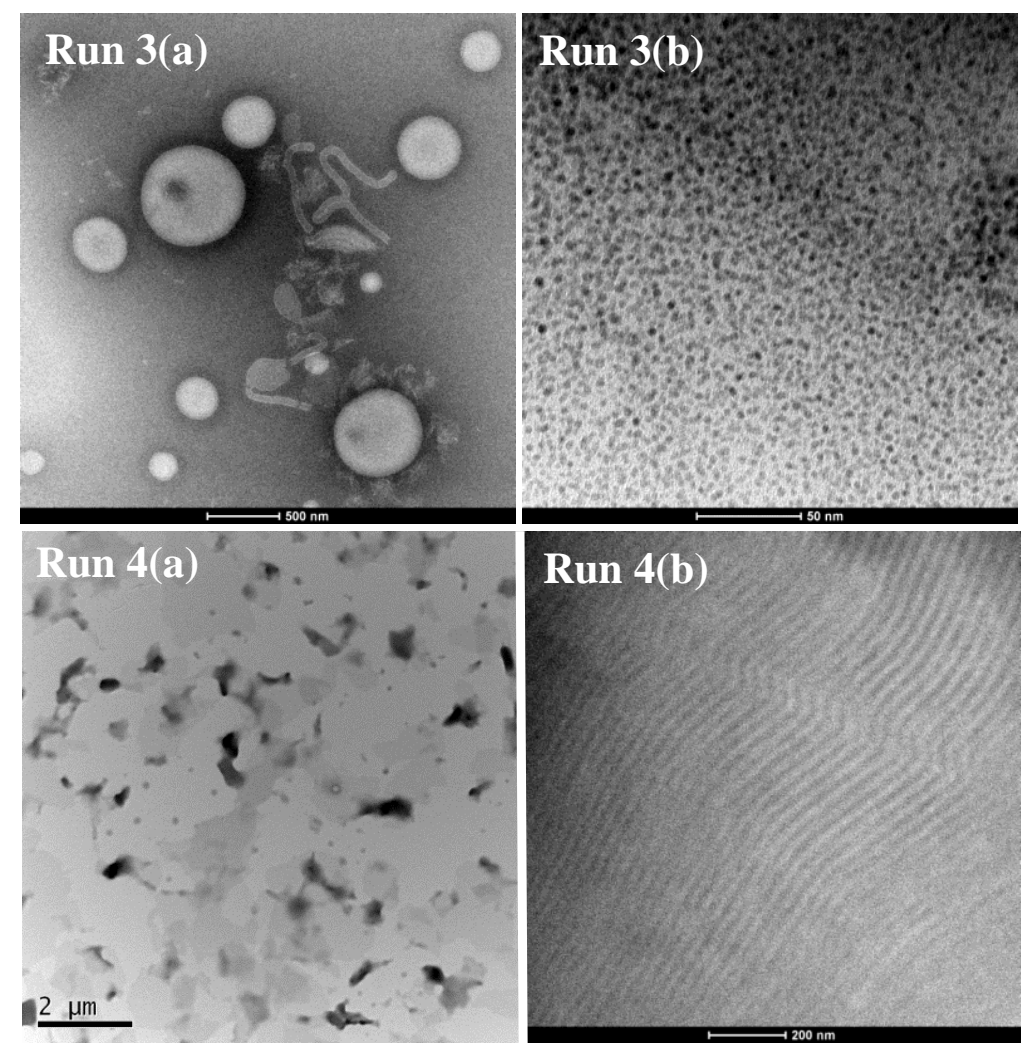

Fig. 3. TEM images of PDMS- $b$-PBzMA particles from Runs 3 and 4 (Table 1) corresponding to dispersion ATRP at $35 \mathrm{v} / \mathrm{v}(\%)$ BzMA in $\mathrm{scCO}_{2}$ at $80{ }^{\circ} \mathrm{C}$ and $30 \mathrm{MPa}$. Scale bars are $500 \mathrm{~nm}$ (Run 3(a)), $50 \mathrm{~nm}$ (Run 3(b)), $2 \mu \mathrm{m}$ (Run 4(a)), and $200 \mathrm{~nm}$ (Run 4(b)).

The effect of monomer loading was investigated (35 v/v(\%) in Runs 1-4 described so far). The lowest loading of $20 \mathrm{v} / \mathrm{v}(\%)$ BzMA resulted in low conversion $(13 \% ; 24 \mathrm{~h})$ and poor controlled/living character as evidenced by a bimodal MWD (Fig. S3). Poor controlled/living character for nitroxide-mediated radical polymerization (NMP) conducted as precipitation polymerization in $\mathrm{scCO}_{2}$ in previous work has been attributed to the high heterogenity of the system. ${ }^{49-52}$ It can be speculated that similar factors are at play in the present ATRP system, with low monomer loadings causing partitioning of reagents (catalyst and ligand) away from the locus of polymerization. The value of $J_{\text {crit }}$ is also expected to decrease with decreasing monomer loading, i.e. particle formation would occur at lower conversion for $20 \mathrm{v} / \mathrm{v}(\%) \mathrm{BzMA}$ loading, ${ }^{32}$ which may cause partitioning effects to become more significant. As the monomer loading was increased beyond $35 \mathrm{v} / \mathrm{v}(\%)$, excellent controlled/living character was maintained as attested by narrow MWDs $(Ð=1.25-1.33)$ and high conversions $(88-94 \%)$ being obtained for 35, 50 and $65 \mathrm{v} / \mathrm{v}(\%)$ after $24 \mathrm{~h}$ (Fig. S3; Runs 3, 5 and 6). 




Fig. 4. TEM images of PDMS- $b$-PBzMA particles from Runs 5 and 6 (Table 1) corresponding to dispersion ATRP at 50 (Run 5) and 65 (Run 6) v/v(\%) BzMA in $\mathrm{scCO}_{2}$ at $80{ }^{\circ} \mathrm{C}$ and $30 \mathrm{MPa}$. Scale bars are $200 \mathrm{~nm}$ (Run 5(a)), $20 \mathrm{~nm}$ (Run 5(b)), and $500 \mathrm{~nm}$ (Run 6(a) and (b)).

Run 5 resulted in a population of small particles $(<20 \mathrm{~nm})$ with phase separated domains, as well as larger particles featuring very clear multilayered lamellar nanostructured regions. Run 6 yielded mainly worms, but also irregulary shaped particles of approx size $100-500 \mathrm{~nm}$.

The particle morphologies obtained via PISA can normally be rationalized based on the packing parameter $(P)$, which is given by the relative volume fractions of the stabilizer (PDMS) and core-forming (PBzMA) blocks. ${ }^{53-54}$ Normally, an increase in the length of the core forming block would result in a transition towards higher order morphologies, i.e. typically from spherical particles to worms and eventually vesicles. The DP of the second block (PBzMA) increases in the order Run 3 (138) < Run 4 (212) < Run 2 (359). These polymerizations were all performed at the same solids content of $35 \mathrm{v} / \mathrm{v} \%$ and all reached similar high conversion. It is clear that the morphologies depicted in the corresponding TEM images (described above) cannot be rationalized based on the relative block lengths. Interestingly, RAFT dispersion PISA in $n$-heptane generating PDMS- $b$-PBzMA at $70{ }^{\circ} \mathrm{C}$ did result in the morphologies evolving from spheres to worms and vesicles as DP of the PBzMA was increased. ${ }^{17}$ Run 2, with the highest DP, would be expected to give the highest order morphology, but this polymerization 
resulted in two distinct solid particle populations of approximate size $300 \mathrm{~nm}$ and $5-30 \mathrm{~nm}$ (Fig. 2), whereas Run 3 with the lowest DP of 138 yielded mixed morphologies including worms (Fig. 3). An increase in vol\% solids content would normally be expected to drive the morphologies towards higher order morphologies. ${ }^{19,}{ }^{55}$ In the present case, we can compare Run 5 (50 vol\% solids) and Run 6 (65 vol\% solids), where the DPs of the second blocks were similar. The increase in solids content is accompanied by the appearance of worms (Run 6), compared to two populations of smaller irregularly shaped particles and a population of larger particles observed in Run 5. This trend appears largely consistent with expectation. Comparing Run 5 with Run 3 (35 vol\% solids and similar DP as Run 5), the morphologies cannot be rationalzed based on the difference in solids content.

The "ideal" PISA morphologies of spheres, worms and vesicles comprise structures where the solvophilic block (PDMS in this case) is not buried within the structure. That is, the solvophilic block is typically in direct contact with the continuous phase. As such, multilayered type morphologies as seen for Runs 4 and 5 are typically not observed in PISA. However, it is well established that microphase separation in the solid state (e.g. in polymer films) can lead to a number of morphologies similar to those observed for Runs 4 and 5. ${ }^{56-59}$ Such microphase separation occurs if the quantity $\chi N$ is sufficiently high, where $\chi$ is the Flory-Huggins segmental interaction parameter and $N$ is the degree of polymerization. ${ }^{59}$ It appears that for the present system, at least under the conditions of Runs 4 and 5, the particle formation process leads to structures where the PDMS segment is buried within the structure itself. One can speculate that the presence of $\mathrm{scCO}_{2}$ and its ability to swell the polymer, in particular the PDMS segment, may facilitate the formation of such structures, unlike in "normal" PISA conducted in conventional solvents such as water and water/alcohol mixtures. Jennings et al. ${ }^{37}$ have reported RAFT dispersion polymerization in $\mathrm{scCO}_{2}$ using a PDMS macromonomer as stabilizer (i.e. not PISA) in an approach that involved sequential polymerization of two different monomers, thus generating diblock copolymers. These authors found that symmetrical copolymers PMMA- $b$ PSt did not result in the expected morphologies (curved cylindrical domains as opposed to the expected lamellar/multilayered morphology), and this was tentatively attributed to different extents of sorption of $\mathrm{CO}_{2}$ into the different polymer domains, consistent with how selective sorption can affect the morphology phase diagram. ${ }^{60}$ Venting of the $\mathrm{CO}_{2}$ would subsequently result in these structures being kinetically trapped. It can be speculated that similar factors play a role in our present PISA system, thus leading to unexpected results in terms of the morphology development. Overall, it appears that the morphologies observed in the present dispersion ATRP in $\mathrm{scCO}_{2}$ cannot be rationalized based on the same general considerations as 
in conventional PISA. It may be that the unique properties of $\mathrm{scCO}_{2}$ as a solvent exert an influence on the PISA process such that the particle morphologies can no longer be broadly rationalized simply based on the packing parameter.

In summary, we have successfully accomplished the first controlled/living dispersion polymerization in $\mathrm{scCO}_{2}$ to give polymer particles of higher order morphology, including worms and likely vesicles. In addition to morphologies typically observed in dispersion PISA, polymer particles with highly regular multilayered morphology were also observed. Based on the present results, it appears that dispersion PISA in $\mathrm{scCO}_{2}$ is not directly comparable to dispersion PISA in commonly employed media such as water and water/alcohol as well as in hydrophobic solvents, possibly as a consequence of the ability of $\mathrm{scCO}_{2}$ to swell polymer particles / polymer domains. Further optimization is required to fully understand and exploit the potential of $\mathrm{scCO}_{2}$ as a medium for PISA.

\section{ASSOCIATED CONTENT}

\section{Supporting Information}

The Supporting Information is available free of charge on the

ACS Publications website at DOI:

\section{Corresponding Authors}

*E-mail: p.zetterlund@unsw.edu.au

*E-mail: f.aldabbagh@kingston.ac.uk

\section{ORCID}

Abdullah Alzahrani: 0000-0003-3195-8142

Dewen Zhou

Per B. Zetterlund: 0000-0003-3149-4464

Fawaz Aldabbagh: 0000-0001-8356-5258

\section{Notes}

The authors declare no competing financial interest.

\section{ACKNOWLEDGMENTS}

We thank the Ministry of Education of the Kingdom of Saudi Arabia for supporting the $\mathrm{PhD}$ of AA. 


\section{References}

1. Houillot, L.; Bui, C.; Save, M.; Charleux, B.; Farcet, C.; Moire, C.; Raust, J. A.; Rodriguez, I., Synthesis of well-defined polyacrylate particle dispersions in organic medium using simultaneous RAFT polymerization and self-assembly of block copolymers. A strong influence of the selected thiocarbonylthio chain transfer agent. Macromolecules 2007, 40 (18), 6500-6509.

2. Houillot, L.; Bui, C.; Farcet, C.; Moire, C.; Raust, J. A.; Pasch, H.; Save, M.; Charleux, B., Dispersion Polymerization of Methyl Acrylate in Nonpolar Solvent Stabilized by Block Copolymers Formed In situ via the RAFT Process. ACS Appl. Mater. Interfaces 2010, 2 (2), 434-442.

3. Sugihara, S.; Sugihara, K.; Armes, S. P.; Ahmad, H.; Lewis, A. L., Synthesis of Biomimetic Poly(2-(methacryloyloxy)ethyl phosphorylcholine) Nanolatexes via Atom Transfer Radical Dispersion Polymerization in Alcohol/Water Mixtures. Macromolecules 2010, 43 (15), 6321-6329.

4. Sugihara, S.; Armes, S. P.; Lewis, A. L., One-Pot Synthesis of Biomimetic Shell Cross-Linked Micelles and Nanocages by ATRP in Alcohol/Water Mixtures. Angew. Chem. Int. Ed. 2010, 49 (20), 3500-3503.

5. Charleux, B.; Delaittre, G.; Rieger, J.; D'Agosto, F., Polymerization-Induced SelfAssembly: From Soluble Macromolecules to Block Copolymer Nano-Objects in One Step. Macromolecules 2012, 45 (17), 6753-6765.

6. Sun, J. T.; Hong, C. Y.; Pan, C. Y., Formation of the block copolymer aggregates via polymerization-induced self-assembly and reorganization. Soft Matter 2012, 8 (30), 7753 7767.

7. Kitayama, Y.; Kishida, K.; Minami, H.; Okubo, M., Preparation of poly(n-butyl acrylate)-b-polystyrene particles by emulsifier-free, organotellurium-mediated living radical emulsion polymerization (emulsion TERP). J. Polym. Sci.; Part A: Polym. Chem. 2012, 50 (10), 1991-1996.

8. $\quad$ Fielding, L. A.; Derry, M. J.; Ladmiral, V.; Rosselgong, J.; Rodrigues, A. M.; Ratcliffe, L. P. D.; Sugihara, S.; Armes, S. P., RAFT dispersion polymerization in non-polar solvents: facile production of block copolymer spheres, worms and vesicles in n-alkanes. Chemical Science 2013, 4 (5), 2081-2087.

9. Zhao, W.; Gody, G.; Dong, S. M.; Zetterlund, P. B.; Perrier, S., Optimization of the RAFT polymerization conditions for the in situ formation of nano-objects via dispersion polymerization in alcoholic medium. Polym. Chem. 2014, 5 (24), 6990-7003.

10. Derry, M. J.; Fielding, L. A.; Armes, S. P., Industrially-relevant polymerizationinduced self-assembly formulations in non-polar solvents: RAFT dispersion polymerization of benzyl methacrylate. Polym. Chem. 2015, 6 (16), 3054-3062.

11. Zhang, Q.; Zhu, S. P., Ionic Liquids: Versatile Media for Preparation of Vesicles from Polymerization-Induced Self-Assembly. ACS Macro Letters 2015, 4 (7), 755-758.

12. Kapishon, V.; Whitney, R. A.; Champagne, P.; Cunningham, M. F.; Neufeld, R. J., Polymerization Induced Self-Assembly of Alginate Based Amphiphilic Graft Copolymers Synthesized by Single Electron Transfer Living Radical Polymerization. Biomacromolecules 2015, 16 (7), 2040-2048.

13. Zetterlund, P. B.; Thickett, S. C.; Perrier, S.; Bourgeat-Lami, E.; Lansalot, M., Controlled/Living Radical Polymerization in Dispersed Systems: An Update. Chem. Rev. 2015, 115 (18), 9745-9800.

14. Pei, Y. W.; Noy, J. M.; Roth, P. J.; Lowe, A. B., Soft Matter Nanoparticles with Reactive Coronal Pentafluorophenyl Methacrylate Residues via Non-Polar RAFT Dispersion Polymerization and Polymerization-Induced Self-Assembly. J. Polym. Sci.; Part A: Polym. Chem. 2015, 53 (20), 2326-2335. 
15. Pei, Y. W.; Sugita, O. R.; Thurairajah, L.; Lowe, A. B., Synthesis of poly(stearyl methacrylate-b-3-phenylpropyl methacrylate) nanoparticles in n-octane and associated thermoreversible polymorphism. RSC Advances 2015, 5 (23), 17636-17646.

16. Pei, Y.; Thurairajah, L.; Sugita, O. R.; Lowe, A. B., RAFT Dispersion Polymerization in Nonpolar Media: Polymerization of 3-Phenylpropyl Methacrylate in n-Tetradecane with Poly(stearyl methacrylate) Homopolymers as Macro Chain Transfer Agents. Macromolecules 2015, 48 (1), 236-244.

17. Lopez-Oliva, A. P.; Warren, N. J.; Rajkumar, A.; Mykhaylyk, O. O.; Derry, M. J.; Doncom, K. E. B.; Rymaruk, M. J.; Armes, S. P., Polydimethylsiloxane-Based Diblock Copolymer Nano-objects Prepared in Nonpolar Media via RAFT-Mediated PolymerizationInduced Self-Assembly. Macromolecules 2015, 48 (11), 3547-3555.

18. Jennings, J.; He, G.; Howdle, S. M.; Zetterlund, P. B., Block copolymer synthesis by controlled/living radical polymerisation in heterogeneous systems. Chem. Soc. Rev. 2016, 45 (18), 5055-5084.

19. Canning, S. L.; Smith, G. N.; Armes, S. P., A Critical Appraisal of RAFT-Mediated Polymerization-Induced Self Assembly. Macromolecules 2016, 49 (6), 1985-2001.

20. Derry, M. J.; Fielding, L. A.; Armes, S. P., Polymerization-induced self-assembly of block copolymer nanoparticles via RAFT non-aqueous dispersion polymerization. Prog.

Polym. Sci. 2016, 52, 1-18.

21. Wang, G.; Schmitt, M.; Wang, Z. Y.; Lee, B.; Pan, X. C.; Fu, L. Y.; Yan, J. J.; Li, S. P.; Xie, G. J.; Bockstaller, M. R.; Matyjaszewski, K., Polymerization-Induced Self-Assembly (PISA) Using ICAR ATRP at Low Catalyst Concentration. Macromolecules 2016, 49 (22), 8605-8615.

22. Zhou, D.; Dong, S.; Kuchel, R. P.; Perrier, S.; Zetterlund, P. B., Polymerization Induced Self-Assembly: Tuning of Morphology using Ionic Strength and pH. Polym. Chem. 2017, 8, 3082-3089.

23. Qiao, X. G.; Lamber, O.; Taveau, J. C.; Dugas, P. Y.; Charleux, B.; Lansalot, M.; Bourgeat-Lami, E., Nitroxide-Mediated Polymerization-Induced Self-Assembly of Block Copolymers at the Surface of Silica Particles: Toward New Hybrid Morphologies.

Macromolecules 2017, 50 (10), 3797-3807.

24. Yeow, J.; Boyer, C., Photoinitiated Polymerization-Induced Self-Assembly (PhotoPISA): New Insights and Opportunities. Advanced Science 2017, 4 (7).

25. Zhou, D. W.; Kuchel, R. P.; Zetterlund, P. B., A new paradigm in polymerization induced self-assembly (PISA): Exploitation of "non-living" addition-fragmentation chain transfer (AFCT) polymerization. Polym. Chem. 2017, 8 (29), 4177-4181.

26. Lotierzo, A.; Schofield, R. M.; Bon, S. A. F., Toward Sulfur-Free RAFT Polymerization Induced Self-Assembly. Acs Macro Letters 2017, 6 (12), 1438-1443.

27. Tan, J. B.; Li, X. L.; Zeng, R. M.; Liu, D. D.; Xu, Q.; He, J.; Zhang, Y. X.; Dai, X. C.; Yu, L. L.; Zeng, Z. H.; Zhang, L., Expanding the Scope of Polymerization-Induced SelfAssembly: Z-RAFT-Mediated Photoinitiated Dispersion Polymerization. ACS Macro Letters 2018, 7 (2), 255-262.

28. Zaquen, N.; Yeow, J.; Junkers, T.; Boyer, C.; Zetterlund, P. B., Visible LightMediated Polymerization-Induced Self-Assembly Using Continuous Flow Reactors. Macromolecules 2018, 51 (14), 5165-5172.

29. Wells, S. L.; DeSimone, J., CO2 technology platform: An important tool for environmental problem solving. Angew. Chem. Int. Ed. 2001, 40 (3), 519-527.

30. Peach, J.; Eastoe, J., Supercritical carbon dioxide: a solvent like no other. Beilstein J. Org. Chem. 2014, 10, 1878-1895. 
31. Zetterlund, P. B.; Aldabbagh, F.; Okubo, M., Controlled/Living Heterogeneous Radical Polymerization in Supercritical Carbon Dioxide. J. Polym. Sci.; Part A: Polym. Chem. 2009, 47 (15), 3711-3728.

32. O'Connor, P.; Zetterlund, P. B.; Aldabbagh, F., Effect of Monomer Loading and Pressure on Particle Formation in Nitroxide-Mediated Precipitation Polymerization in Supercritical Carbon Dioxide. Macromolecules 2010, 43 (2), 914-919.

33. McHale, R.; Aldabbagh, F.; Zetterlund, P. B.; Minami, H.; Okubo, M., Nitroxidemediated radical dispersion polymerization of styrene in supercritical carbon dioxide using a poly(dimethylsiloxane-b-methyl methacrylate) stabilizer. Macromolecules 2006, 39 (20), 6853-6860.

34. Gregory, A. M.; Thurecht, K. J.; Howdle, S. M., Controlled dispersion polymerization of methyl methacrylate in supercritical carbon dioxide via RAFT. Macromolecules 2008, 41 (4), 1215-1222.

35. Grignard, B.; Jerome, C.; Calberg, C.; Jerome, R.; Wang, W.; Howdle, S. M.; Detrembleur, C., Copper bromide complexed by fluorinated macroligands: towards microspheres by ATRP of vinyl monomers in scCO(2). Chem. Commun. 2008, (3), 314-316. 36. Grignard, B.; Jerome, C.; Calberg, C.; Jerome, R.; Detrembleur, C., Atom transfer radical polymerization of MMA with a macromolecular ligand in a fluorinated solvent and in supercritical carbon dioxide. Eur. Polym. J. 2008, 44 (3), 861-871.

37. Jennings, J.; Beija, M.; Richez, A. P.; Cooper, S. D.; Mignot, P. E.; Thurecht, K. J.; Jack, K. S.; Howdle, S. M., One-Pot Synthesis of Block Copolymers in Supercritical Carbon Dioxide: A Simple Versatile Route to Nanostructured Microparticles. J. Am. Chem. Soc. 2012, 134 (10), 4772-4781.

38. Xia, J. H.; Johnson, T.; Gaynor, S. G.; Matyjaszewski, K.; DeSimone, J., Atom transfer radical polymerization in supercritical carbon dioxide. Macromolecules 1999, 32 (15), 4802-4805.

39. Minami, H.; Kagawa, Y.; Kuwahara, S.; Shigematsu, J.; Fujii, S.; Okubo, M., Dispersion atom transfer radical polymerization of methyl methacrylate with bromoterminated poly(dimethylsiloxane) in supercritical carbon dioxide. Designed Monomers and Polymers 2004, 7 (6), 553-562.

40. Ryan, J.; Aldabbagh, F.; Zetterlund, P. B.; Okubo, M., First nitroxide-mediated free radical dispersion polymerizations of styrene in supercritical carbon dioxide. Polymer 2005, 46 (23), 9769-9777.

41. McHale, R.; Aldabbagh, F.; Zetterlund, P. B.; Okubo, M., Nitroxide-mediated radical dispersion polymerization of styrene in supercritical carbon dioxide using a poly(dimethyl siloxane-block-styrene) alkoxyamine as initiator and stabilizer. Macromol. Rapid Commun. 2006, 27 (17), 1465-1471.

42. Grignard, B.; Phan, T.; Bertin, D.; Gigmes, D.; Jerome, C.; Detrembleur, C., Dispersion nitroxide mediated polymerization of methyl methacrylate in supercritical carbon dioxide using in situ formed stabilizers. Polym. Chem. 2010, 1 (6), 837-840.

43. Kuroda, T.; Tanaka, A.; Taniyama, T.; Minami, H.; Goto, A.; Fukuda, T.; Okubo, M., Iodine transfer dispersion polymerization (dispersion ITP) with CHI3 and reversible chain transfer catalyzed dispersion polymerization (dispersion RTCP) with GeI4 of styrene in supercritical carbon dioxide. Polymer 2012, 53 (6), 1212-1218.

44. Hasell, T.; Thurecht, K. J.; Jones, R. D. W.; Brown, P. D.; Howdle, S. M., Novel one pot synthesis of silver nanoparticle-polymer composites by supercritical $\mathrm{CO} 2$ polymerisation in the presence of a RAFT agent. Chem. Commun. 2007, (38), 3933-3935.

45. Zong, M. M.; Thurecht, K. J.; Howdle, S. M., Dispersion polymerisation in supercritical CO(2) using macro-RAFT agents. Chem. Commun. 2008, (45), 5942-5944. 
46. Lee, H.; Terry, E.; Zong, M.; Arrowsmith, N.; Perrier, S.; Thurecht, K. J.; Howdle, S. M., Successful dispersion polymerization in supercritical $\mathrm{CO} 2$ using polyvinylalkylate hydrocarbon surfactants synthesized and anchored via RAFT. J. Am. Chem. Soc. 2008, 130 (37), 12242-+.

47. Birkin, N. A.; Wildig, O. J.; Howdle, S. M., Effects of poly(vinyl pivalate)-based stabiliser architecture on $\mathrm{CO} 2$-solubility and stabilising ability in dispersion polymerisation of N-vinyl pyrrolidone. Polym. Chem. 2013, 4 (13), 3791-3799.

48. Huan, K.; Bes, L.; Haddleton, D. M.; Khoshdel, E., Synthesis and properties of polydimethylsiloxane-containing block copolymers via living radical polymerization. $J$. Polym. Sci.; Part A: Polym. Chem. 2001, 39 (11), 1833-1842.

49. McHale, R.; Aldabbagh, F.; Zetterlund, P. B.; Okubo, M., Nitioxide-mediated radical precipitation polymerization of styrene in supercritical carbon dioxide. Macromol. Chem. Phys. 2007, 208 (16), 1813-1822.

50. Aldabbagh, F.; Zetterlund, P. B.; Okubo, M., Improved control in nitroxide-mediated radical polymerization using supercritical carbon dioxide. Macromolecules 2008, 41 (7), 2732-2734.

51. Aldabbagh, F.; Zetterlund, P. B.; Okubo, M., Nitroxide-mediated precipitation polymerization of styrene in supercritical carbon dioxide: Effects of monomer loading and nitroxide partitioning on control. Eur. Polym. J. 2008, 44 (12), 4037-4046.

52. Magee, C.; Earla, A.; Petraitis, J.; Higa, C.; Braslau, R.; Zetterlund, P. B.; Aldabbagh, F., Synthesis of fluorinated alkoxyamines and alkoxyamine-initiated nitroxide-mediated precipitation polymerizations of styrene in supercritical carbon dioxide. Polym. Chem. 2014, 5 (19), 5725-5733.

53. Israelachvili, J. N.; Mitchell, D. J.; Ninham, B. W., Theory of self-assembly of hydrocarbon amphiphiles into micelles and bilayers. Journal of the Chemical Society Faraday Transactions Ii 1976, 72, 1525-1568.

54. Blanazs, A.; Armes, S. P.; Ryan, A. J., Self-Assembled Block Copolymer Aggregates: From Micelles to Vesicles and their Biological Applications. Macromol. Rapid Commun. 2009, 30 (4-5), 267-277.

55. Mai, Y. Y.; Eisenberg, A., Self-assembly of block copolymers. Chem. Soc. Rev. 2012, 41 (18), 5969-5985.

56. Bates, F. S., Polymer-polymer phase-behavior. Science 1991, 251 (4996), 898-905.

57. Bates, F. S.; Fredrickson, G. H., Block copolymers - Designer soft materials. Physics Today 1999, 52 (2), 32-38.

58. Luo, M.; Epps, T. H., Directed Block Copolymer Thin Film Self-Assembly: Emerging Trends in Nanopattern Fabrication. Macromolecules 2013, 46 (19), 7567-7579. 59. Sun, Z. W.; Zhang, W. X.; Hong, S.; Chen, Z. B.; Liu, X. H.; Xiao, S. G.; Coughlin, E. B.; Russell, T. P., Using block copolymer architecture to achieve sub-10 nm periods. Polymer 2017, 121, 297-303.

60. Lodge, T. P.; Pudil, B.; Hanley, K. J., The full phase behavior for block copolymers in solvents of varying selectivity. Macromolecules 2002, 35 (12), 4707-4717. 


\section{Graphical Abstract}
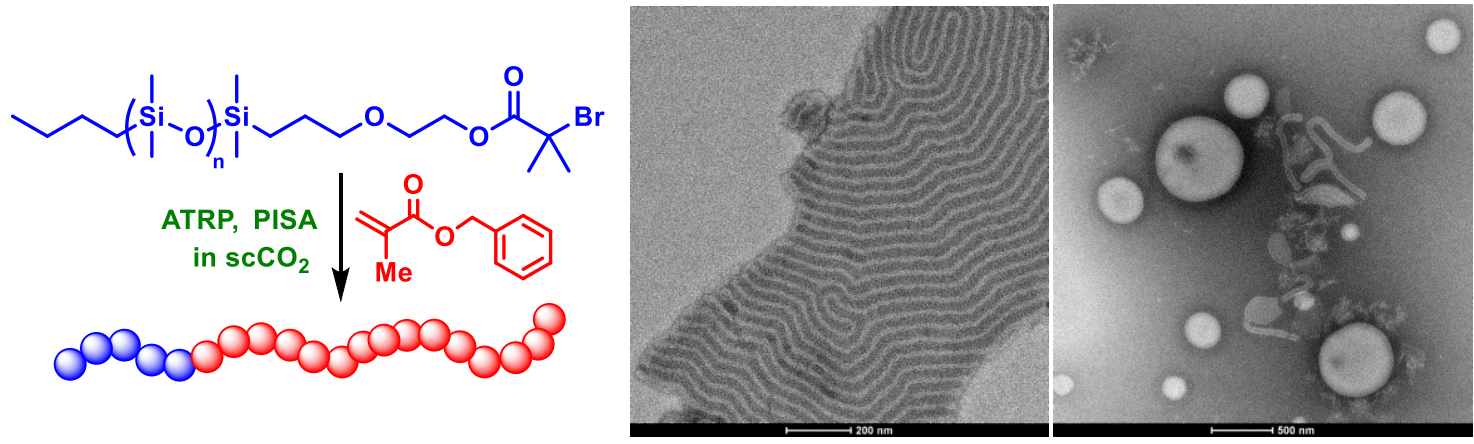